\title{
PEMANFAATAN BIG DATA UNTUK PERCEPATAN PROSES UNDERWRITING SEBAGAI STRATEGI KOMUNIKASI MARKETING TERPADU PERUSAHAAN ASURANSI JIWA
}

\author{
Annisa Khairani, Irwansyah \\ Magister Manajemen Ilmu Komunikasi Fakultas Ilmu Sosial dan Ilmu Politik \\ Universitas Indonesia \\ annisakhairani.mkomui@gmail.com
}

\begin{abstract}
In the fast-paced era like now, the demand for effective and efficient business processes is increasing, not least in the insurance industry. One of the things that can increase the acceleration of business processes is the utilization of big data in the industry. Big data is important, those who can take advantage of big data will have a strong and fast base in making business decisions including the insurance company Allianz. Utilizing big data in accelerating business processes in the insurance industry, especially at PT. Allianz Life Indonesia insurance occurs in the process of accelerating underwriting with an automatic underwriting system so that it can be one of the selling points in the marketing process of corporate communications to customers. The presence of this automatic underwriting system replaces the role of human underwriters by the system so that the role of underwriters will be increased to process prospective customer data that is more complex and requires analysis that is not contained in the system. The company expands into new markets by highlighting the advantages of a faster and simpler underwriting process that is supported by the use of Big Data and more sophisticated analysis as one of the marketing communication strategies. The purpose of this conceptual paper is to explain how big data management can be used as one of the insurance company's marketing communication strategies.
\end{abstract}

Keywords: Big Data, Underwriting, Communication Marketing Strategy

\begin{abstract}
Abstrak
Dalam era serba cepat seperti sekarang, tuntutan proses bisnis yang efektif dan efisien makin meningkat tak terkecuali dalam industri asuransi. Salah satu hal yang dapat meningkatkan percepatan proses bisnis adalah pemanfaatan big data dalam industri. Big data merupakan hal yang penting, mereka yang bisa memanfaatkan big data akan memiliki dasar yang kuat dan cepat dalam pengambilan keputusan bisnis termasuk perusahaan asuransi Allianz. Pemanfaatan big data dalam mempercepat proses bisnis di industri asuransi terutama di PT. Asuransi Allianz Life Indonesia terjadi pada proses percepatan underwriting dengan system underwriting otomatis sehingga dapat menjadi salah satu nilai jual dalam proses marketing komunikasi perusahaan pada nasabah. Kehadiran system underwriting otomatis ini menggantikan peran underwriter manusia oleh system sehingga peran underwiter akan ditingkatkan untuk memproses data calon nasabah yang lebih kompleks dan membutuhkan analisa yang tidak terdapat di dalam system. Perusahaan berekspansi ke dalam pasar baru dengan menonjolkan keunggulan proses underwriting yang lebih cepat dan lebih simpel yang didukung dengan penggunaaan Big Data dan analisis yang lebih canggih sebagai salah satu stretegi marketing komunikasi. Tujuan dari konseptual paper ini untuk menjelaskan bagaimana pemnafaatan big data dapat digunakan sebagai salah satu strategi marketing komunikasi perusahaan asuransi.
\end{abstract}

Kata Kunci: Big Data, Underwriting, Strategi marketing komunikasi 


\section{PENDAHULUAN}

Dewasa ini peran komunikasi sangat penting bagi semua aspek kehidupan termasuk aspek ekonomi masyarakat, Ilmu Komunikasi makin berkembang pesat hingga digunakan untuk tujuan-tujuan pemasaran. Salah satu alat komunikasi yang digunakan pada bidang pemasaran adalah Integrated Marketing Communication (IMC) atau dalam bahasa Indonesia komunikasi marketing terpadu, dimana pada abad 21 ini IMC sudah lazim digunakan pada berbagai macam produk baik barang maupun jasa. Salah satu bidang pemasaran yang memanfaatkan IMC dalam aktivitas industrinya adalah jasa asuransi. IMC sudah cukup umum digunakan dalam dunia asuransi dari perusahaan asuransi baru dan berkembang, hingga perusahaan-perusahaan asuransi besar. Sebelum membahas lebih jauh tentang IMC pada industri asuransi, berikut beberapa definisi tentang asuransi.

Istilah asuransi sendiri mempunya beberapa definisi berbeda, definisidefinisi tersebut didasarkan pada sudut pandang yang berbeda-beda dalam meninjau asuransi. Berikut adalah beberapa sudut pandang para ahli dalam mendefinisikan asuransi: definisi asuransi menurut Green (1991) : "Asuransi adalah suatu lembaga ekonomi yang bertujuan mengurangi risiko, dengan jalan mengkombinasikan dalam suatu pengelolaan sejumlah obyek yang cukup besar jumlahnya, sehingga kerugian tersebut secara menyeluruh dapat diramalkan dalam batas-batas tertentu".

Definisi asuransi menurut C.Arthur dan Richard M. Heins (1997) yang mendefinisikan asuransi berdasarkan dua sudut pandang, yaitu: asuransi adalah suatu pengaman terhadap kerugian finansial yang dilakukan oleh seorang penanggung. Dan asuransi adalah suatu persetujuan dengan mana dua atau lebih orang atau badan mengumpulkan dana untuk menanggulangi kerugian finansial.

Jika kita tarik kesimpulan berdasarkan definisi-definisi tersebut diatas, maka pengertian Asuransi secara garis besar adalah alat yang digunakan untuk mengurangi resiko, dengan menggabungkan sejumlah unit-unit yang mempunyai resiko yang sama atau hampir sama dalam jumlah memadai, agar probabilitas dapat diramalkan dan dapat disalurkan kepada unit yang mengalami resiko.

Indonesia pertama kali mengenal asuransi pada waktu penjajahan Belanda. Industri asuransi di Indonesia terus berkembang, dengan peluang usaha yang besar dan potensi pasar yang menggiurkan, hal ini dapat dilihat dari rasio kepemilikan unit asuransi yang masih kecil jika dibandingkan dengan jumlah penduduk Indonesia yang besar. Kondisi tersebut membentuk lingkungan industri yang sarat persaingan. Perusahaan-perusahaan asuransi bersaing dengan berbagai macam cara yang berbeda, agar mempunyai daya saing tinggi dan menghasilkan keuntungan yang maksimal. Dari aspek tarif mereka menawarkan tarif premi terendah dalam menggaet pemegang polis, Dari sudut pandang masyarakat, harga produk asuransi memang menjadi murah, namun total volume premi yang tidak meningkat secara signifikan menyebabkan beban asuransi dalam menghadapi potensi klaim menjadi meningkat, sehingga persaingan pada aspek tarif dinilai kurang sehat.

Selain itu juga industri asuransi nasional tidak luput dari kendala-kendala 
dan permasalahan-permasalahan tertentu, misalnya kurangnya edukasi dan awareness masyarakat Indonesia tentang pentingnya asuransi. Bertolak belakang dengan pemahaman negara-negara maju tentang asuransi yang mengintegrasikan edukasi asuransi didalam kurikulum dasar pendidikan, sehingga pemahaman dan awareness masyarakat tentang asuransi sudah diterima dengan baik. Masyarakat Indonesia secara umum masi minim dalam kesadaran keuangan dan pentingnya asuransi, sehingga edukasi berkelanjutan yang melibatkan seluruh komponen industri asuransi sangat penting, agar secara jangka panjang dapat meningkatkan kepercayaan masyarakat terhadap perusahaan asuransi. Permasalahan jangka pendek yang sering dihadapi industri asuransi adalah ketidakpercayaan terhadap proses klaim dan lamanya proses terbitnya polis asuransi.

Beberapa perusahaan melakukan ekspansi ke pasar baru dengan menonjolkan keunggulan proses underwriting yang lebih cepat dan simple dengan menggunakan analisis big data. Misalnya, salah satu perusahaan Asuransi internasional yang ada di Indonesia, PT. Allianz Life Indonesia yang sudah menggunakan system underwriting otomatis bernama Expert Underwriting System (EUS) sehingga mengoptimalkan pengalaman berasuransi nasabah. Pemanfaatan analisis big data dapat membantu perusahaan menjadi lebih efisien dan meningkatkan kepuasan nasabah terhadap layanan perusahaan asuransi.

Berdasarkan uraian diatas maka agar dapat memperkuat daya saing dan menyelesaikan masalah-masalah yang dihadapi, perusahaan asuransi membutukan komunikasi marketing terpadu atau yang sering disebut Integrated Marketing Communication (IMC) dengan memanfaatkan analisis big data sebagai nilai tambah marketing.

\section{TINJAUAN PUSTAKA}

\section{Big Data, Data Mining, Underwriting}

Perkembangan teknologi yang sangat pesat menyebabkan munculnya era baru yang disebut era digital. Keberadaan teknologi digital berdampak pada terjadinya revolusi data, dimana data yang sebelumnya hanya berjumlah kecil dan tersedia secara terbatas kini telah berevolusi menjadi jumlah besar yang dapat diperoleh dari berbagai sumber secara cepat. Kondisi inilah yang kemudian memunculkan suatu konsep saat ini sedang popular yang disebut Big Data. Big Data merupakan data yang mempunyai tiga karakteristik, yaitu jumlah (volume) yang besar, variasi (variety) yang tinggi, dan dapat dihasilkan dengan cepat (velocity), sehingga melampaui kapasitas pengolahan database konvensional (Dumbill, 2014).

Dibandingkan dengan dataset tradisional, big data pada umumnya merupakan jenis data tidak terstruktur yang memerlukan analisis real-time. Selain itu, big data juga membawa peluang baru untuk menemukan berbagai nilai baru, membantu untuk memperoleh pemahaman mendalam tentang nilai-nilai tersembunyi, dan juga mendorong terciptanya tantangan baru, misalnya, cara efektif mengatur dan mengelola dataset tersebut (Chen, Mao, \& Liu, 2014).Dengan banyaknya jumlah data yang ada, analisis mengenai data tersebut perlu dilakukan untuk mendapatkan 
informasi dan pengetahuan yang tersimpan didalamnya. Pada analisis kasus Big Data, metode yang biasanya digunakan adalah Data Mining. Secara umum, Data Mining dapat diartikan sebagai separangkat mekanisme dan teknik untuk mendapatkan informasi yang penting (hidden information) dari data. Pada awal 1990-an Data Mining dikenal sebagai Knowledge Discovery from Database, meskipun dalam konteks modern, Data Mining akan lebih tepat apabila disebut sebagai Knowledge Discovery from Data (KDD) (Jiawei, Kamber, \& Pei, 2012). Beberapa tahapan proses KDD, yaitu seleksi data, pembersihan data, transformasi data, pencarian pola (Data Mining), serta menginterpretasi dan evaluasi. Data mining mampu mengekstrak koleksi data yang besar (big data) menjadi suatu bentuk informasi yang berguna dalam rangka penyelesaian masalah dan pemenuhan tantangan global saat ini.

Mekanisme Data Mining sangat bervariasi karena terdapat banyak pola pada database yang memiliki jumlah besar. Metode dan teknik yang berbeda dibutuhkan untuk menemukan pola yang berbeda. Berdasarkan jenis pola yang dicari, mekanisme Data Mining dapat diklasifikasikan menjadi beberapa jenis, diantaranya

Summarization, Classification, Clustering, Association, dan Trend Analysis. (Fu, 2015). Data Mining dapat digunakan untuk mengolah dan menganalisis data yang bersifat terstruktur seperti data numerik, kontinyu dan interval. Untuk data yang bersifat semi terstruktur (semi structured) dan tidak terstruktur (unstructured) digunakan Text Mining yang pada dasarnya merupakan bagian dari Data Mining. Text Mining pertama kali dikembangkan pada tahun 1980-an dan telah menjadi semakin efektif seiring dengan daya komputasi yang meningkat. Text Mining telah sukses dalam menemukan berbagai pola dan koneksi pada data yang berbentuk teks, salah satunya adalah publikasi ilmiah pada jurnal internasional (Basole, et.al, 2013).

Dalam buku silabus Asosiasi Ahli Manajemen Asuransi Indonesia, Underwriting adalah proses penganalisaan risiko. Seorang underwriter seperti tugas koki, dia yang menentukan apakah " bahan baku " yang ditawarkan dapat diolah menjadi “" masakan " yang layak makan ataukah tidak. Tugas itu merupakan sebuah elemen yang esensial dalam operasi suatu perusahaan, sebab pada akhirnya maksud underwriting adalah untuk memaksimalkan laba melalui penerimaan distibusi risiko yang diperkirakan akan mendatangkan laba. Tanpa underwriting yang efisien, suatu perusahaan tidak akan mampu bersaing. Dan, untuk mengukur tingkat keuntungan dari usaha murni perusahaan asuransi salah satunya dapat dilihat dari rasio underwriting yaitu rasio yang menunjukkan tingkat hasil underwriting yang dapat diperoleh perusahaan

\section{Integreted Marketing Communication}

Dalam Shimp (2003), dijelaskan bahwa terdapat lima ciri yang melekat pada filosofi dan aplikasi dari komunikasi pemasaran terpadu (IMC). Kelima ciri tersebut adalah:

1. Mempengaruhi perilaku: Tujuan dari IMC adalah untuk mempengaruhi perilaku khalayak sasarannya. Hal ini berarti komunikasi pemasaran harus 
'memperbaiki' perilaku konsumen terhadap merek.

2.

Berawal dari pelanggan dan calon pelanggan (prospect) : Proses IMC diawali dari pelanggan atau calon pelanggan, kemudian berbalik kepada komunikator merek untuk menentukan metode yang paling tepat dan efektif dalam mengembangkan program komunikasi persuasif.

3. Menggunakan satu atau segala cara untuk melakukan 'kontak' IMC menggunakan seluruh bentuk komunikasi dan seluruh 'kontak' yang menghubungkan merek atau perusahaan dengan pelanggan mereka.

4.

Berusaha menciptakan sinergi: Semua elemen komunikasi (iklan, tempat pembelian, promosi penjualan, event, dan lain-lain) haruslah memiliki koordinasi yang baik untuk menghasilkan citra merek yang kuat dan utuh, serta dapat membuat konsumen melakukan aksi.

5. Menjalin hubungan Merupakan kepercayaan bahwa komunikasi pemasaran yang sukses membutuhkan terjalinnya hubungan antara merek dengan pelanggannya.

Pada akhirnya konsep integrated marketing communication menjadi lebih luas. Dari hanya sekedar untuk kepentingan pemasaran produk, menjadi lebih komprehensif dan menyeluruh bagi perusahaan.

Elemen-elemen komunikasi tersebut digunakan untuk mecapai tujuan- tujuan komunikasi dan pemasaran tersebut dirumuskan menjadi The Promotional Mix (Belch 2009). Adapun beberapa elemen yang terdapat di dalam The Promotional Mix ini adalah sebagai berikut:

Advertising: merupakan bentuk persuasif dari marketing communication yang dirancang untuk menstimulasi tanggapan positif dari target pasar yang telah didefinisikan. Advertising mencakup segala bentuk komunikasi non-personal melalui berbagai media massa seperti TV, radio, majalah dan koran mengenai informasi tentang perusahaan, produk dan jasa atau ide sebuah sponsor yang dikenal. Elemen komunikasi ini paling banyak digunakan pemasar karena dapat menjangkau target audience dalam jumlah besar.

Direct Marketing: merupakan sebuah aktivitas pemasaran yang dilakukan oleh perusahaan secara langsung kepada konsumennya. Umumnya aktivitas pemasaran ini dilakukan dengan cara mengirimkan direct mail, melakukan telemarketing dan direct selling kepada konsumen yang dituju. Untuk dapat melakukan hubungan secara langsung dengan para konsumen potensialnya maka perusahaan mengelola data based konsumen.

Interactivel Internet Marketing: aktivitas pemasaran yang dilakukan secara interaktif melalui CD-ROMs, handphone digital, TV interaktif dan lain sebagainya atau secara online menggunakan jaringan internet untuk mengkomunikasikan produk dan jasanya. Melalui aktivitas ini, perusahaan dan konsumen dapat melakukan komunikasi 2 arah langsung secara real- time.

Sales Promotion: aktivitas pemasaran yang dilakukan dengan cara memberikan nilai incentive kepada tim penjualan, distributor, atau konsumennya secara langsung untuk mendorong penjualan dengan cepat. Sales promotion yang dilakukan kepada konsumen biasanya dengan membagikan sample produk, kupon dan lain sebagainya untuk 
mendorong konsumen agar langsung melakukan pembelian. Sedangkan sales promotion yang dilakukan kepada distributor dan pedagang dilakukan dalam bentuk kontes penjualan, pemberian harga khusus, penyediaan merchandising dan masih banyak lagi bentuk lainnya.

Publicity and Public Relations: sama halnya dengan advertising, publikasi/ public relations adalah komunikasi nonpersonal melalui berbagai media massa seperti $\mathrm{TV}$, radio, majalah dan koran mengenai perusahaan, produk, jasa atau sponsor acara yang didanai langsung atau tidak langsung yang dilakukan dalam bentuk news release, press conference, artikel, film dan lain-lain. Bedanya dengan advertising adalah, untuk masuk ke jaringan media massa perusahaan tidak mengeluarkan dana khusus melainkan menyediakan berita seputar produk dan jasa, melakukan event atau aktivitas lain yang menarik untuk diliput atau dipublikasikan oleh media massa. Sedangkan public relation adalah fungsi manajemen yang dilakukan untuk mengevaluasi perilaku publik, mengedentifikasi kebijakan dan prosedur individu atau organisasi terhadap public interest, serta mengeksekusi sebuah program untuk dapat diterima dan dipahami oleh publik. Tujuan utama melakukan public relation adalah untuk menciptakan dan mengelola image positif perusahaan di mata publik yang biasanya dilakukan dengan cara melakukan pengumpulan dana, mensponsori acara khusus, berpartisipasi dalam aktivitas sebuah komunitas dan masih banyak lagi yang lainnya.

Personal Selling adalah aktivitas komunikasi yang dilakukan secara langsung oleh pihak penjual untuk meyakinkan pembeli potensial membeli produk atau jasa yang ditawarkan. Melalui aktivitas komunikasi ini, penjual dapat memodifikasi pesan komunikasi agar sesuai dengan kebutuhan dan keinginan konsumen serta mendapatkan feedback langsung dari konsumennya. Dalam bukunya, Tuckwell (2008) juga menjelaskan bahwa elemen berperan untuk saling menghubungkan dan mempengaruhi secara strategissecara simultan. Elem komunikasi ini berpengaruh secara efektif dalam membantu pemasaran produk dan jasa, tujuan agar pesan yang disampaikan produsen bisa diterima secara aktif oleh pembeli Pemilihan elemen komunikasi pemasaran terpadu ini akan kembali lagi melihat pada karakter dari produk atau jasa yang akan dipasarkan (Arens \& Bovee, 1995). Shimp (2003:163) proses komunikasi pemasaran terdiri dari sumber, encoding, pesan, saluran, penerima, decoding, noise, umpan balik.

\section{HASIL DAN PEMBAHASAN}

\section{Industri Asuransi \& Proses Underwriting}

Lembaga keuangan dianggap sebagai financial intermediary artinya pihak yang mempunyai kelebihan dana (surplus of funds) dengan pihak yang kekurangan dana (lack of funds), sehingga peranan lembaga keuangan sesungguhnya adalah sebagai perantara keuangan atau dana masyarakat (FinancialIntermediary, artinya yang luas lembaga keuangan tersebut termasuk didalamnya lembaga perbankan, perasuransian, dana pensiun, penggadaian dan lain-lain yang menjadi jembatan antara pihak yang kelebihan 
dana dengan pihak yang memerlukan dana. Dalam hal lembaga asuransi, peranannya di Indonesia adalah untuk menanggung atau menjamin seseorang terhadap kerugian-kerugian finansial (Djumhana, 2000). Asuransi dikembangkan untuk menghasilkan pemecahan praktis bagi ketidakpastian dan kerugian ekonomis. Untuk memberikan kepastian di dalam pelaksanaan perjanjian pertanggungan, harus diatur secara jelas mengenai ketentuan tugas masing-masing pihak baik hak maupun kewajibannya. Hal ini dimaksudkan untuk menghindari hal-hal yang tidak diinginkan dimana pihak yang dipercayakan untuk menanggulangi risiko benar-benar mengetahui bahwa hal tersebut memang telah diperjanjikan sebelumnya.

Risiko adalah ketidakpastian yang memungkinkan lahirnya peristiwa kerugian (loss) (Redja, 2007). Risiko muncul apabila tidak ada kepastian mengenai masa depan. Perorangan maupun perusahaan menghadapi dua macam resiko yaitu speculative risk dan pure risk. Speculative risk (resiko spekulatif) memiliki tiga kemungkinan hasil yaitu rugi, untung atau tidak ada perubahan (Jones, 1991). Untuk meminimalisir dampak dari resiko tersebut maka diperlukan jasa asuransi.

Di Indonesia, untuk istilah asuransi sering digunakan istilah pertanggungan. Kedua istilah ini tampaknya mengikuti istilah dalam bahasa Belanda, yaitu assurantie (asuransi) dan verzekering (pertanggungan). Memang asuransi di lndonesia bermula dari negeri Belanda. Di Inggris digunakan istilah insurance dan assurance yang mempunyai pengertian yang sama. Istilah insurance digunakan untuk asuransi kerugian sedangkan istilah assurance digunakan untuk asuransi jiwa.

Jadi secara lengkap dapat disimpulkan bahwa definisi asuransi adalah suatu perjanjian kontrak antara penanggung dengan tertanggung dalam perjanjian mana penanggung berjanji akan mengganti setiap kerugian yang diderita oleh penanggung akibat dari suatu risiko yang disebutkan dalam perjanjian, risiko mana belum diketahui atau belum terjadi pada saat perjanjian diadakan. Meskipun menunjukkan peningkatan, namun masih terdapat masalah yang dihadapi oleh industri asuransi saat ini, terutama masih rendahnya permodalan perusahaan asuransi sehingga secara umum perusahaan asuransi akan menghadapi kesulitan untuk melakukan penutupan risiko berskala besar dan rentan terhadap risiko keuangan yang timbul.

Atas kesediaan perusahaan asuransi sebagai penanggung yang memberikan penggantian seperti tersebut diatas, ia menerima sejumlah uang yang disebut premi. Antara peserta dan badan asuransi terjalin suatu ikatan perjanjian dimana peserta (tertanggung) diwajibkan membayar sejumlah dana (biasanya secara berkala) kepada badan asuransi (penanggung) yang disebut premi. Besarnya premi yang harus dibayarkan ini tergantung dari kesepakatan tentang jenis pelayanan kesehatan yang ditanggung. Secara umum disebutkan jika jenis pelayanan kesehatan yang ditanggung bervariasi dan lengkap, maka jumlah premi yang dibayarkan akan besar pula. Perjanjian secara hukum antara penanggung dan tertanggung ini disebut polis. Dalam polis inilah tercantum tentang hak dan kewajiban 
yang harus dipatuhi oleh masing-masing pihak.

\section{Strategi Komunikasi Terpadu (Integrated Maketing Communication / IMC)}

Dalam perkembangan perusahaanperusahaan modern, diketahui bahwa saat ini integrasi antara elemen-elemen komunikasi dan pemasaran adalah kunci penting dalam meraih sukses. Tetapi seringkali perusahaan-perusahaan cenderung menempatkan elemen-elemen komunikasi sebagai aktivitas yang terpisah dari kegiatan pemasaran, solusi dari fenomena tersebut adalah IMC. IMC adalah konsep yang berkembang sejak tahun 1980 dan mempunyai beberapa definisi menurut para ahli antara lain:

Schultz (2004), IMC adalah sebuah strategi dalam proses bisnis dengan membuat perencanaan, membangun, mengeksekusi dan mengevaluasi pelaksanaan program komunikasi merek yang terkoordinasi pada konsumen, pelanggan, atau sasaran lain yang relevan dengan audience eksternal dan internal. The 4As (The American Association of Advertising Agency) mengatakan bahwa IMC adalah konsep perencanaan komunikasi pemasaran yang matang dengan mengevaluasi peran masingmasing bentuk komunikasi pemasaran (periklanan umum, sales promotion, public relations dan lain- lain) dan memadukan bentuk-bentuk komunikasi pemasaran ini untuk memberikan kejelasan, konsistensi dan dampak komunikasi yang maksimal (Belch 2009).

Shimp (2010) mendefinisikan IMC sebagai sebuah proses komunikasi yang terdiri dari perencanaan, penciptaan, pengintegrasian dan penerapan berbagai bentuk komunikasi pemasaran (iklan, sales promotion, publikasi, event dan lain sebagainya). Jika kita tinjau uraian para ahli diatas maka dapat kita tarik pengertian IMC berdasarkan definisi-definisi tersebut; IMC adalah sebuah konsep komunikasi yang berstrategi, dan terencana, yang diterapkan dalam berbagai bentuk komunikasi pemasaran, yang dipilih spesifik untuk memberikan dampak maksimal melalui konsistensi pesan, kepada terget audience tertentu mengenai produk yang dikomunikasikan.

Seiring perkembangan IMC, Kitchen et al (2004) memberikan poin tersendiri bahwa IMC bukan lagi hanya sebuah proses komunikasi, tetapi sebuah proses yang terkait dengan pengelolaan sebuah brand. IMC melibatkan cara pengelolaan komunikasi pemasaran secara holistic untuk mencapai tujuan strategis, IMC mewujudkan sinergi, kreativitas, integrasi dan komunikasi pemasaran secara terpadu dengan cara memanfaatan beragam elemen komunikasi yang berbeda-beda agar tercipta koherensi yang saling mendukung (Rangkuti, 2010).

\section{PENUTUP}

\section{Simpulan dan Saran}

Perusahaan modern, diketahui bahwa saat ini integrasi antara elemenelemen komunikasi dan pemasaran adalah kunci penting dalam meraih sukses. Tetapi seringkali perusahaan-perusahaan cenderung menempatkan elemen-elemen komunikasi sebagai aktivitas yang terpisah dari kegiatan pemasaran, solusi dari fenomena tersebut adalah IMC.

Kebersediaan asuransi untuk melakukan perubahan sistem membuat terobosan baru tentang pemanfaatan big data. Strategi komunikasi yang tepat 
memudahkan penggunaan big data dalam mengoptimalisasi komunikasi pemasaran asuransi. Perusahaan cenderung menempatkan elemen-elemen komunikasi sebagai aktivitas yang terpisah dari kegiatan pemasaran, solusi dari fenomena tersebut adalah IMC (Integrated Maketing Communication).

\section{DAFTAR PUSTAKA}

Arens, Alvin A, JK Loebbecke, 1995. Auditing. Adaptasi Amir Abadi Yusuf. Edisi 5. Jakarta: Salemba Empat.

Basole, R. C., Seuss, C. D., \& Rouse, W. B. (2013). IT innovation adoption by enterprises : Knowledge discovery thtough text analytics. Decision Support System 54, 10441054.

Belch, George E \& Belch, Michael A. 2009. Advertising and Promotion. New York: McGraw-Hill / Irwin.

C. Arthur Williams Jr. and Richard M. Heins, 1987, Risk Management and Insurance, fifth edition, Mc. GrawHill Book Company

Chen, M., Mao, S., \& Liu, Y. (2014, January 22). Big Data: A Survey. Mobile Network Application , 171209.

Djumhana, Muhammad. 2000. Hukum Perbankan Di Indonesia.Bandung : PT Citra Aditya Bakti

Dumbill, E. (2014, July 5). Forbes Magazine. Forbes Magazine Web Site:

http://www.forbes.com/sites/edddu mbill /2014/05/07/defining-bigdata/. Diakses pada 3 Maret 2015

Fu, Y. (2015). Data Mining : Tasks, Techniques, and Application. Retrieved from Computer Science
Ohio:

http://academic.csuohio.edu/fuy/Pu b/pot97.pdf

Green, W. 1991. Health Promotion Planning An Education and Environmental Approach. Second Edition. Columbia: Mayfield Publishing Company.

Jiawei, H., Kamber, M., \& Pei, J. (2012). Data Mining : Concept and Techniques Third Edition. Waltham, MA: Morgan Kaufman.

Jones, Jennifer J, 1991. Earnings Management During Import ReliefInvestigations. Journal Of Accounting Research, Vol 29, No. 2 1991, p.193- 228

Kitchen, Philip J. et al. 2004. Integrated Marketing Communications: A primer. New York: Routledge Taylor \& Francis Group.

Rangkuti, Freddy. 2010. Strategi Promosi yang Kreatif \&Analisis kasus Integrated Marketing Communication. Jakarta: PT.Gramedia Pustaka Utama.

Redja, G. 2007. Risk Management and Insurance. (International Edition). USA : Pearson Education Inc

Schultz, Don E \& Lauterborn, Robert F. 2004. Integrated Marketing Communications. USA: NTC Bussiness Books.

Shimp, a Terrence. 2003. Advertising and Promotion \& Suplemental Aspects of Integrated Marketing Communications, Sixth Edition, Thomson South- Western. Ohio

Tuckwell, Keith. 2008. Integrated Marketing Communications:Strategic Planning Perspectives. Canada:Pearson 